\title{
How Many Harberger Triangles Does it Take to Fill one Okun Gap?
}

Max Planck Institute for Tax Law and Public Finance

Working Paper 2016 - 05

March 2016

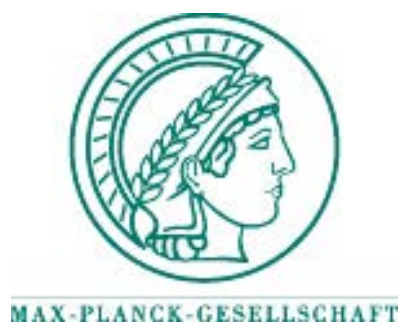

Max Planck Institute for

Tax Law and Public Finance

Department of Business and Tax Law

Department of Public Economics

http:/ /www.tax.mpg.de 
Working papers of the Max Planck Institute for Tax Law and Public Finance Research Paper Series serve to disseminate the research results of work in progress prior to publication to encourage the exchange of ideas and academic debate. Inclusion of a paper in the Research Paper Series does not constitute publication and should not limit publication in any other venue. The preprints published by the Max Planck Institute for Tax Law and Public Finance represent the views of the respective author(s) and not of the Institute as a whole. Copyright remains with the author(s).

Max Planck Institute for Tax Law and Public Finance

Marstallplatz 1

D-80539 Munich

Tel: $\quad+498924246-0$

Fax: $\quad+498924246-501$

E-mail: ssrn@tax.mpg.de

http://www.tax.mpg.de 


\title{
How many Harberger triangles does it take to fill one Okun gap?
}

\author{
Aart Gerritsen*
}

\author{
March 2016
}

At least one; at most a heap.

JEL codes: H21; J21; E24

Keywords: Economic costs of rationing, economic costs of taxation

\section{INTRODUCTION}

An Okun gap represents the economic costs of underemployment of productive factors (Okun, 1962). A Harberger triangle represents the economic costs of distorted employment of productive factors (Harberger, 1964a,b). The two measures of economic inefficiency are associated with separate fields of economics - the former with macro-, the latter with microeconomics. But every now and then, in an apparent attempt to ascertain the relative importance of either field, economists venture to ask how many Harberger triangles it takes to fill one Okun gap. A first tentative answer came from James Tobin when he conjectured that it takes a heap of Harberger Triangles to fill an Okun Gap' (Tobin, 1977, p.468). While Tobin's conjecture is regularly rehashed in popular debates on economics, the non-specific nature of his answer - a heap - is rather unsatisfactory for more quantitatively oriented economists. Stephen Williamson, for example, seems unconvinced that there is any difference at all between an Okun gap and a Harberger triangle when he states that:

* Max Planck Institute for Tax Law and Public Finance, Department of Public Economics, Marstallplatz 1, 80539 Munich, Germany. Tel.: +49-89-24246-5256; Fax: +4989-24246-5299; E-mail: aart.gerritsen@tax.mpg.de; Internet: https://sites.google. com/site/aartgerritsen/. 
[i]t takes a heap of Harberger triangles to fill a heap of Harberger triangles. ... The inefficiencies that arise in New Keynesian models are indeed identical to the ones which would be generated by a set of good-specific taxes. ... If I argue that Keynesian sticky wage/price distortions are large, and that tax distortions are small, that's a contradiction. ${ }^{1}$

Thus, Williamson conjectures that it merely takes one Harberger triangle to fill an Okun gap. Paul Krugman, on the other hand, seems convinced that it really does take a heap of Harberger triangles when he states that:

Macro Trumps Micro. Or, as the late James Tobin used to say, it takes a lot of Harberger triangles to fill an Okun gap. ... [I]t's a more general observation that even bad microeconomic policies, which lead to substantial distortions in the use of resources, have a hard time doing remotely as much damage as a severe economic slump, which doesn't misallocate resources it simply wastes them. ${ }^{2}$

In an ultimate attempt to bring the two rival camps closer together, N. Gregory Mankiw calls for more rigorous research on the matter to enable us to quantitatively determine the number of triangles that fit in a gap:

That [i.e., Tobin's conjecture] is a great slogan for the Keynesian team. But I agree ... that it would be better to go beyond quips and try to quantify the issue with real data and real models. ${ }^{3}$

Unfortunately, there is no clear agreed-upon way of determining the number of Harberger triangles that fit in one Okun gap - which is where this paper comes in.

Focussing on the labor market, I propose a straightforward approach to compare the economic costs of demand shortage with the economic costs of supply distortions. The key is to acknowledge that supply distortions lead people to voluntarily exit the labor market, whereas a demand shortage

\footnotetext{
${ }^{1}$ Stephen Williamson. Gaps and Triangles. From his weblog, New Monetarist Economics, 9 December 2012.

${ }^{2}$ Paul Krugman. Macro Trumps Micro. From his weblog, The Conscience of a Liberal, 7 December 2012.

${ }^{3}$ N. Gregory Mankiw. Triangles vs Gaps. From his weblog, Greg Mankiw's Blog, 13 January 2009.
} 
causes involuntary unemployment, or labor rationing. When the job allocation under rationing is efficient, demand shortage and supply distortions are equally wasteful. However, when rationing is inefficient, the economic costs of demand shortage could easily trump the economic costs of supply distortions. Hence, it takes at least one Harberger triangle to fill an Okun gap, but potentially many more. I moreover show that the number of Harberger triangles per Okun gap represents a measure of the economic gains that could be made by raising taxes in a rationed labor market. By discouraging labor supply, higher taxes could substitute supply distortions for demand shortage. Finally, I determine the relative marginal economic costs of labor rationing and tax distortions for a given reduction in employment, and provide upper- and lower-bound calculations for a large number of OECD countries.

\section{ON TRIANGLES AND GAPS}

The labor supply and demand diagrams in Figure 1 provide a visual representation of how one could go about answering the Title's question. For ease of exposition, assume that individuals either work and provide one unit of labor at some given wage rate, or do not work at all. The upward-sloping supply curve represents the fact that individuals differ in their reservation wages. The downward-sloping demand curve represents a production technology that is strictly concave in employment. The intersection of $L^{d}$ and $L_{0}^{s}$ represents the efficient market equilibrium. The first graph illustrates a case in which there is no distinction between a Harberger triangle and an Okun gap. Distorting labor supply - for example by imposing a proportional income tax - results in a new market equilibrium represented by the intersection of $L^{d}$ and $L_{1}^{s}$. This distorted equilibrium yields a producer surplus equal to Area I, and an aggregate worker surplus cum tax revenue equal to Area II. The economic waste is given by the Harberger triangle in Area III.

But labor rationing could lead to the exact same allocation of jobs. If, for some reason, the wage rate $w$ is above its market-clearing level, employment is determined by the intersection of $L^{d}$ and $w$ even though labor supply is determined by the intersection of $L_{0}^{s}$ and $w$. As a result, 
a. A Harberger triangle / minimal Okun gap

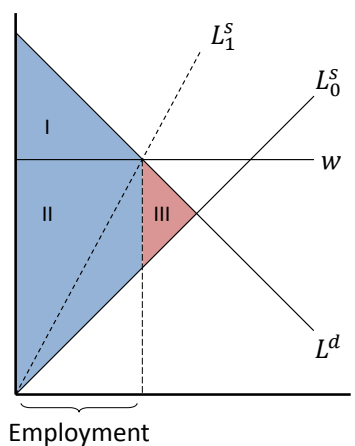

b. A maximal Okun gap

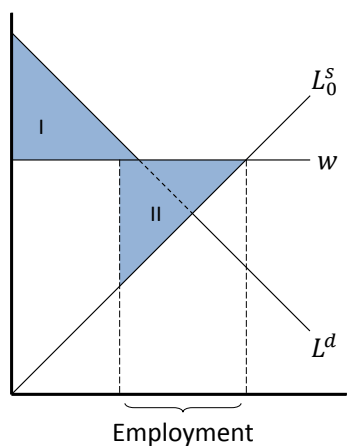

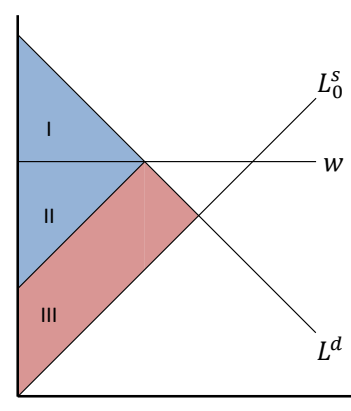

Figure 1: Harberger triangles and Okun gaps

there are more individuals willing to work than there are jobs, leading to labor rationing or involuntary unemployment. If rationing is efficient, in the sense that only those individuals with the lowest reservation wages manage to obtain a job, producer and worker surplus are again given by Areas I and II in the first graph of Figure 1. The economic waste associated with labor rationing is then given by Area III. In other words: it takes exactly one Harberger triangle to fill the Okun gap.

However, this is just one of many possible allocations of scarce jobs among those willing to work. In the absence of a secondary market for jobs, there is little reason to assume that rationing is efficient (e.g., Tobin, 1952; Bulow and Klemperer, 2012). ${ }^{4}$ After all, firms have no incentive to discriminate between individuals with identical productivity but different reservation wages. It is therefore conceivable that the limited amount of available jobs could be distributed among any of the individuals that are willing to work at the going wage rate. The second and third graphs in Figure 1 illustrate a scenario of extremely inefficient rationing in which only those individuals with the highest reservation wages obtain a job. Worker surplus is given by Area II, and the economic waste associated with rationing is given by Area III. As drawn, it is obvious that the economic

\footnotetext{
${ }^{4}$ Indeed, empirical studies point at significant inefficiencies associated with allocating rationed goods, e.g., Glaeser and Luttmer (2003); Davis and Kilian (2011); Deacon and Sonstelie (1989); Frech and Lee (1987). Perhaps because of the difficulties involved in measuring reservation wages, there is little evidence on the efficiency of labor rationing, and whatever evidence we do have is mixed, e.g., Luttmer (2007).
} 
costs of reducing employment through rationing is much higher than the economic costs of reducing employment through supply distortions. Indeed, one might be tempted to say that it takes a heap of Harberger triangles to fill the Okun gap.

This graphical analysis provides a first rough answer to the title question. It takes at least one Harberger triangle to fill an Okun gap, and potentially many more. The exact answer crucially depends on the efficiency of the ration, as well as on the shape of the labor supply curve. The quarrel between Williamson and Krugman, rather than being a matter of fundamental discord, could therefore be reduced to a disagreement about the efficiency of labor rationing. In stating that it takes only one Harberger triangle to fill an Okun gap, Williamson implicitly assumes that rationing is efficient. Krugman (and Tobin), in stating that it takes a lot of Harberger triangles, implicitly assumes that rationing is very inefficient. As there is little reason to presume that rationing is efficient, it is indeed likely that more than one Harberger triangle fits in an Okun gap. Furthermore notice that, if rationing is inefficient, the analysis of Figure 1 implies that raising income taxes might enhance efficiency in a rationed labor market (cf. Gerritsen, 2016). Higher taxes cause the labor supply curve to rotate counter-clockwise, replacing involuntary unemployment (and its Okun gap) by voluntary unemployment (and its Harberger triangle). Thus, the number of Harberger triangles that fit into an Okun gap gives an indication of the economic gains that can be made by raising taxes in a rationed labor market.

\section{MARGINAL TRIANGLES AND MARGINAL GAPS}

It is possible to be more precise by focussing on the economic costs of marginal changes in employment. For a given marginal reduction in employment, how much more costly is it if the reduction is caused by rationing rather than by tax distortions? That is, how many 'marginal Harberger triangles' does it take to fill one 'marginal Okun gap'? To answer these questions, I focus on an economy with preexisting distortions such as the one illustrated in Figure 2. Here, $L^{d}$ again depicts labor demand as a function of gross wages, $L_{0}^{s}$ depicts labor supply as a function of net-of-tax 
wages, and $L_{1}^{s}$ depicts labor supply as a function of gross wages, with $t$ a proportional income tax. The distorted equilibrium is represented by the intersection of $L_{1}^{s}$ and $L^{d}$, and the red triangle represents the economic waste associated with this preexisting distortion.

First consider the economic costs of an increase in the tax distortion. Higher taxes cause the labor-supply curve to further rotate counterclockwise, leading individuals with the lowest utility surplus of work to drop out of the labor market. These individuals are represented by the segment of the labor supply curve that is labeled 'efficient' on the horizontal axis in Figure 2. Because they are indifferent between participation and non-participation, their utility remains unaffected. Only the government loses out as tax revenue declines with the reduction in employment. The economic costs of a marginal increase in tax distortions thus consists of a tax-revenue loss equal to $t w$, as illustrated by the red line segment $A B .^{5}$

Now consider the economic costs of an increase in rationing. Again, lower employment leads to a reduction of tax revenue equal to $t w$. On top of that, individuals that are rationed out of the labor market might suffer a utility loss, the size of which is represented by the vertical distance between the net wage and the labor supply curve $L_{0}^{s}$ in Figure 2. The total utility loss of an increase in rationing crucially depends on the efficiency of the ration - i.e., on the utility surplus of those who are rationed. At one extreme, if rationing is efficient, the rationed individuals are represented by the segment on the labor supply curve labeled 'efficient.' In that case, there is no additional utility loss associated with rationing so that it takes exactly one marginal Harberger triangle to fill one marginal Okun gap. Intuitively, efficient rationing and tax distortions cause the exact same individuals to drop out of the labor market. At the other extreme, if rationing is very inefficient, the rationed individuals could be represented by the origin of Figure 2. In that case, rationed individuals suffer a utility loss equal to their entire net wage income, $(1-t) w{ }^{6}$ The economic costs of rationing

\footnotetext{
${ }^{5}$ I abstract from general equilibrium effects. That is, I ignore the possibility that reductions in employment change the demand and supply of complementary production factors, thereby affecting possible preexisting distortions in the market for those factors. Moreover, as the focus of the paper is on the economic costs or dead-weight losses associated with tax distortions and labor rationing, I ignore redistributive issues.

${ }^{6}$ Naturally, this is driven by the implicit assumption that the labor supply curve passes through the origin. It is easy to provide reasons why this might not necessarily
} 


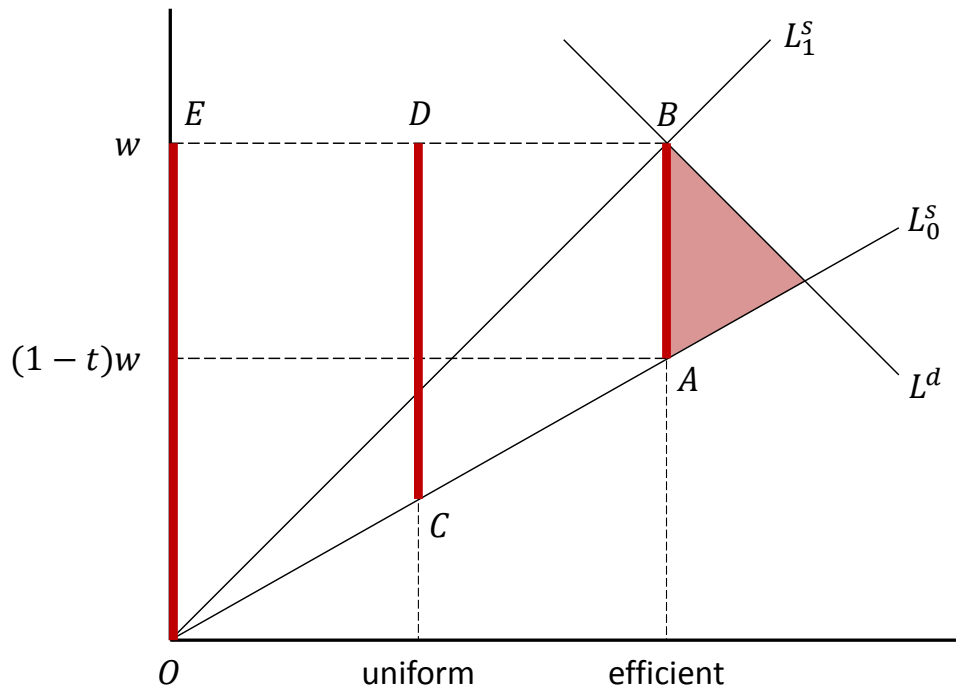

Figure 2: Marginal Harberger triangle and marginal Okun gap for a given reduction in employment

Table 1: How many Harberger triangles to fill an Okun gap?

\begin{tabular}{cccc}
\hline Tax rate & Upper bound & Uniform rationing & Lower bound \\
\hline 0.00 & $\infty$ & $\infty$ & 1.0 \\
0.10 & 10.0 & 5.5 & 1.0 \\
0.20 & 5.0 & 3.0 & 1.0 \\
0.30 & 3.3 & 2.2 & 1.0 \\
0.40 & 2.5 & 1.8 & 1.0 \\
0.50 & 2.0 & 1.5 & 1.0 \\
0.60 & 1.7 & 1.3 & 1.0 \\
0.70 & 1.4 & 1.2 & 1.0 \\
0.80 & 1.3 & 1.1 & 1.0 \\
0.90 & 1.1 & 1.1 & 1.0 \\
\hline
\end{tabular}

The upper-bound and uniform-rationing values are conditional on the assumption that the labor supply curve goes through the origin, and on the assumption that the reduction in employment does not affect other tax bases (e.g., due to general equilibrium effects). The uniform-rationing values are conditional on the assumption that the labor supply curve is linear. Upperbound values are given by $1 / t$, uniform-rationing values by $(1+\mathrm{t}) / 2 \mathrm{t}$, lowerbound values by 1 . 
is then illustrated by the red line segment $O E$. The marginal Okun gap equals gross wage income, $w$, and it takes $w / t w=1 / t$ marginal Harberger triangles to fill the gap.

Thus, on the margin, it takes at least one and at most $1 / t$ Harberger triangles to fill an Okun gap. Both extremes - associated with efficient rationing and extremely inefficient rationing - have little intuitive appeal. It seems implausible that an increase in labor rationing always hits individuals with either the highest or the lowest reservation wages. An intermediate case, which might be more reasonable, is that of uniform rationing - in which every worker faces the same probability of being rationed. The economic costs of uniform rationing is represented by the red line segment $C D$ in Figure 2. It equals the loss in tax revenue, $t w$, as well as the expected utility loss, $(1-t) w / 2$, which equals half of the utility loss of extremely inefficient rationing. ${ }^{7}$ This yields a marginal Okun gap of $t w+(1-t) w / 2$, which takes $(1+t) / 2 t$ marginal Harberger triangles to fill.

\section{SOME ECONOMIC COST CALCULATIONS}

Table 1 provides calculations of the economic costs of rationing relative to tax distortions, for a given marginal reduction in employment. It does so for various levels of preexisting tax distortions, and for extremely inefficient rationing ('Upper bound'), uniform rationing, and efficient rationing ('Lower bound'). A number of things stand out. First, in the absence of preexisting distortions, non-efficient rationing is infinitely more wasteful than taxation. The reason is the well-known result that the economic costs of taxation are second-order in the absence of any preexisting distortions. Second, the relative costs of non-efficient rationing quickly decline with the level of preexisting taxes. With a 10-percent tax rate, rationing is between one and ten times more wasteful than taxation; with a 50-percent tax rate, rationing is only between one and two times more wasteful.

hold, but it is not obvious whether the maximum utility loss for a rationed individual should be larger or smaller than the net wage. Valuable leisure suggests that individuals have strictly positive reservation wages; the existence of charity workers and the idea that employment might be intrinsically valuable to people - or unemployment intrinsically hurtful - suggests that some individuals' reservation wages might be negative.

${ }^{7}$ This requires the assumption that labor supply curves are linear. The utility loss under uniform rationing would be larger (smaller) with convex (concave) supply curves. 
Table 2: How many Harberger triangles to fill an Okun gap? (II)

\begin{tabular}{|c|c|c|c|c|c|c|}
\hline \multirow[b]{2}{*}{ Country } & \multicolumn{3}{|c|}{ Long-term tax rates } & \multicolumn{3}{|c|}{ Short-term tax rates } \\
\hline & $\mathrm{t}$ & UB & UR & $\mathrm{t}$ & UB & UR \\
\hline Greece & 0.04 & 23.8 & 12.4 & 0.92 & 1.1 & 1.0 \\
\hline Italy & 0.08 & 11.8 & 6.4 & 0.75 & 1.3 & 1.2 \\
\hline Slovak Republic & 0.31 & 3.3 & 2.1 & 0.41 & 2.5 & 1.7 \\
\hline United States & 0.31 & 3.2 & 2.1 & 0.58 & 1.7 & 1.4 \\
\hline Israel & 0.41 & 2.5 & 1.7 & 0.74 & 1.4 & 1.2 \\
\hline Portugal & 0.44 & 2.3 & 1.6 & 0.81 & 1.2 & 1.1 \\
\hline Spain & 0.44 & 2.3 & 1.6 & 0.74 & 1.4 & 1.2 \\
\hline Estonia & 0.46 & 2.2 & 1.6 & 0.62 & 1.6 & 1.3 \\
\hline Hungary & 0.47 & 2.1 & 1.6 & 0.86 & 1.2 & 1.1 \\
\hline Australia & 0.49 & 2.0 & 1.5 & 0.49 & 2.0 & 1.5 \\
\hline Korea & 0.52 & 1.9 & 1.5 & 0.30 & 3.3 & 2.1 \\
\hline France & 0.53 & 1.9 & 1.4 & 0.76 & 1.3 & 1.2 \\
\hline Poland & 0.53 & 1.9 & 1.4 & 0.79 & 1.3 & 1.1 \\
\hline Canada & 0.54 & 1.8 & 1.4 & 0.73 & 1.4 & 1.2 \\
\hline Ireland & 0.57 & 1.7 & 1.4 & 0.64 & 1.6 & 1.3 \\
\hline New Zealand & 0.62 & 1.6 & 1.3 & 0.62 & 1.6 & 1.3 \\
\hline Belgium & 0.64 & 1.6 & 1.3 & 0.77 & 1.3 & 1.1 \\
\hline United Kingdom & 0.64 & 1.6 & 1.3 & 0.65 & 1.5 & 1.3 \\
\hline Finland & 0.65 & 1.5 & 1.3 & 0.82 & 1.2 & 1.1 \\
\hline Austria & 0.66 & 1.5 & 1.3 & 0.78 & 1.3 & 1.1 \\
\hline Czech Republic & 0.66 & 1.5 & 1.3 & 0.82 & 1.2 & 1.1 \\
\hline Sweden & 0.68 & 1.5 & 1.2 & 0.88 & 1.1 & 1.1 \\
\hline Norway & 0.70 & 1.4 & 1.2 & 0.86 & 1.2 & 1.1 \\
\hline Luxembourg & 0.70 & 1.4 & 1.2 & 0.89 & 1.1 & 1.1 \\
\hline Germany & 0.72 & 1.4 & 1.2 & 0.82 & 1.2 & 1.1 \\
\hline Iceland & 0.73 & 1.4 & 1.2 & 0.84 & 1.2 & 1.1 \\
\hline Japan & 0.75 & 1.3 & 1.2 & 0.67 & 1.5 & 1.2 \\
\hline Netherlands & 0.76 & 1.3 & 1.2 & 0.82 & 1.2 & 1.1 \\
\hline Slovenia & 0.79 & 1.3 & 1.1 & 0.91 & 1.1 & 1.0 \\
\hline Chile & 0.80 & 1.2 & 1.1 & 0.93 & 1.1 & 1.0 \\
\hline Denmark & 0.96 & 1.0 & 1.0 & 0.94 & 1.1 & 1.0 \\
\hline
\end{tabular}

$t$ gives the 2009 participation tax rate associated with moving from longor short-term unemployment to full-time work at fifty percent of the average wage. Besides labor-income related taxation, it incorporates social, housing, and family benefits, and, for the short-term measure, unemployment benefits. Data shown are the averages of the participation tax rate for four demographic groups: single parent, two children; one-earner married couple, two children, spouse inactive; single; two-earner married couple, two children, spouse earning 67 percent of the average wage. 'UB' and 'UR' give the upper-bound and uniform-rationing values of the number of marginal Harberger triangles it takes to fill one marginal Okun gap. Upper-bound values are given by $1 / t$; uniform-rationing values by $(1+t) / 2 t$.

Source: OECD (2011) and author's calculations, available on request. 
With actual data on tax rates, I can calculate the relative wastefulness of rationing for a large number of countries. To this end, Table 2 provides data on participation tax rates in various countries, taken from OECD (2011). A participation tax rate (PTR) measures the additional tax revenue as a percentage of full-time income, from an individual who moves from either long-term or short-term unemployment to full-time work. Table 2 reports both long- and short-term measures of the PTR for people who earn fifty percent of the their country's average wage income when working - which is an income group that tends to be especially vulnerable to labor rationing. Based on these PTRs, I calculate the economic costs of rationing relative to the economic costs of taxation. Table 2 reports an upper-bound value based on extremely inefficient rationing ('UB') and an intermediate value based on uniform rationing ('UR'), for both long- and short-term rationing.

Again two things stand out from Table 2. First, when it concerns shortterm rationing, there is hardly any difference between the economic costs of higher rationing and the economic costs of higher taxation. The reason is that short-term PTRs are relatively high. This implies that the government absorbs most of the material losses when a person is being rationed out of his job. For all OECD countries, individuals are to a large extent insured against the income losses of short-term unemployment, and consequently suffer relatively small utility losses from a temporary loss of employment. As a result, even the upper-bound economic costs of extremely inefficient rationing is much less than double the economic costs of tax distortions for almost every country.

Second, things are decidedly different when it comes to long-term unemployment. Participation tax rates are often much lower in the long run when the unemployed are no longer entitled to unemployment benefits. As a result, the unemployed might carry a potentially large part of the total economic costs of long-term rationing. This finding is particularly worrisome when we observe, from Table 2, that this holds especially for South-European countries - Greece and Italy, and to a lesser extent Spain and Portugal - that currently face relatively high unemployment rates that might persist for a long time to come. Thus, for some of the countries that currently suffer most from long-term unemployment, it may indeed take a heap of Harberger triangles to fill their Okun gap. 


\section{CONCLUSION}

Tobin's conjecture - it takes a heap of Harberger triangles to fill an Okun gap - has been an invaluable quote for economists who wish to simultaneously deplore inadequate demand for labor and downplay concerns about microeconomic distortions. This paper elaborates on how to compare the economic costs of demand shortage with the economic costs of supply distortions, thereby quantifying the number of Harberger triangles it might take to fill one Okun gap. I show that this comparison is meaningful beyond gleeful discussions on the relative merits of macro- and microeconomics. Indeed, the number of Harberger triangles that fits in one Okun gap represents a measure of the economic gains that could be made by raising supply distortions in rationed labor markets - thereby replacing involuntary unemployment (and its Okun gap) by voluntary unemployment (and its Harberger triangle). The rough calculations provided in this paper suggest that significant economic gains might be made by raising taxes in some of the countries that currently experience high long-term unemployment rates.

\section{References}

Bulow, Jeremy and Paul Klemperer. 2012. "Regulated prices, rent seeking, and consumer surplus." Journal of Political Economy 120 (1):160-186.

Davis, Lucas W and Lutz Kilian. 2011. "The allocative cost of price ceilings in the U.S. residential market for natural gas." Journal of Political Economy 119 (2):212-241.

Deacon, Robert T and Jon Sonstelie. 1989. "The welfare costs of rationing by waiting." Economic Inquiry 27 (2):179-196.

Frech, Harry E and William C Lee. 1987. "The welfare cost of rationingby-queuing across markets: Theory and estimates from the U.S. gasoline crises." The Quarterly Journal of Economics 102 (1):97-108.

Gerritsen, Aart. 2016. "Equity and efficiency in rationed labor markets." Mimeo. 
Glaeser, Edward L. and Erzo F.P. Luttmer. 2003. "The misallocation of housing under rent control." The American Economic Review 93 (4):1027-1046.

Harberger, Arnold C. 1964a. "The measurement of waste." American Economic Review 49 (2):134-146.

. 1964b. "Taxation, resource allocation, and welfare." In The Role of Direct and Indirect Taxes in the Federal Revenue System, edited by John F. Due. Princeton: Princeton University Press, 25-80.

Luttmer, Erzo F. P. 2007. "Does the Minimum Wage Cause Inefficient Rationing?" BE Journal of Economic Analysis $\&$ Policy 7 (1). (Contributions, Article 49).

OECD. 2011. "Taxation and Employment." OECD Tax Policy Studies No. 21, OECD Publishing, Paris.

Okun, Arthur M. 1962. "Potential GNP: Its measurement and significance." Proceedings of the Business and Economic Statistics Section of the American Statistical Association :98-104.

Tobin, James. 1952. "A Survey of the Theory of Rationing." Econometrica $20(4): 521-553$.

—. 1977. "How dead is Keynes?" Economic Inquiry 15 (4):459-468. 